\title{
Theoretical Study about the Effect of Halogen Substitution on the Reactivity of Antitumor 3-Formylchromones and Their Free Radicals
}

\author{
Maximiliano Martínez-Cifuentes, ${ }^{1}$ Boris Weiss-López, ${ }^{2}$ and Ramiro Araya-Maturana ${ }^{3}$ \\ ${ }^{1}$ Programa Institucional de Fomento a la Investigación, Desarrollo e Innovación, Universidad Tecnológica Metropolitana, \\ Ignacio Valdivieso 2409, Casilla 9845, 8940577 Santiago, Chile \\ ${ }^{2}$ Departamento de Química, Facultad de Ciencias, Universidad de Chile, Las Palmeras 3425, Casilla 653, 7800003 Santiago, Chile \\ ${ }^{3}$ Instituto de Química de Recursos Naturales, Universidad de Talca, Av. Lircay s/n, Casilla 747, 3460000 Talca, Chile
}

Correspondence should be addressed to Maximiliano Martínez-Cifuentes; mmartinez@utem.cl and Ramiro Araya-Maturana; raraya@utalca.cl

Received 29 December 2016; Accepted 2 February 2017; Published 21 February 2017

Academic Editor: Pedro M. Mancini

Copyright (C) 2017 Maximiliano Martínez-Cifuentes et al. This is an open access article distributed under the Creative Commons Attribution License, which permits unrestricted use, distribution, and reproduction in any medium, provided the original work is properly cited.

\begin{abstract}
The mandatory presence of a chlorine atom on the aromatic ring of 6-hydroxy-3-formyl angular chromones, on the respiration inhibition of mammary carcinoma mouse, is explained through a computational study of these compounds. This study analyzes the reactivity of the neutral molecules and their free radicals, in gas phase and with water solvation, incorporated by the polarizable continuum medium (PCM) approach. Electrophilic reactivities were evaluated using Fukui $\left(f^{+}\right)$and Parr $\left(P^{+}\right)$functions. The stabilities of radical species formed by the abstraction of a hydrogen atom from the $\mathrm{O}-\mathrm{H}$ bond were evaluated by bond dissociation enthalpy (BDE) and spin density (SD) calculations. This study has potential implications for the design of chromone analogues as anticancer compounds.
\end{abstract}

\section{Introduction}

Chromones are a group of natural oxygen-containing heterocyclic compounds, with a benzoannelated $\gamma$-pyrone ring; this motif is the core fragment of several flavonoids $[1,2]$. The biological actions exhibited by this type of compounds include cytotoxic [2-4], neuroprotective [5, 6], HIV-inhibitory [7, 8], antimicrobial [9], antifungal [10], antioxidant [11, 12], and antidiabetics $[13,14]$ activities. Also they have been evaluated as cardiovascular agents calpain inhibitors [15] and calcium antagonists [16]. In cancer studies, activities such as cell cycle arrest, induction of apoptosis and differentiation, inhibition of angiogenesis, antioxidation, and reversal of multidrug resistance have been identified [17]. Some flavonoids have already entered clinical trials; for example, flavopiridol, identified as the first cyclin dependent kinase inhibitor, entered phase II clinical trials [18]. Besides, stigmatellin A, a chromone isolated from the myxobacterium Stigmatella aurantiaca, is a powerful inhibitor of electron transport in mitochondria and chloroplasts [19]. Stigmatellin is one of the most potent inhibitors of the ubiquinol oxidation site (Qo site) of complex-III [20], although some chromones have also shown interesting activities on NADH: ubiquinone reductase (complex I) [21, 22].

The ethylenic double bond of 4-oxo-4H-benzopyran-3carbaldehyde (3-formyl chromone) is a very reactive system towards nucleophiles, owing to the presence of aldehydic and pyrone carbonyl groups linked to it [23]. This feature makes these compounds susceptible to nucleophilic attack, inside the cell, resulting in covalent modifications of the nucleophilic sites present in biological molecules, such as thiols and amine groups in proteins. On the other hand, phenolic compounds may either stimulate or inhibit oxidative damage to biomolecules, acting as antioxidants or 
TABLE 1: Bond dissociation energies (kcal/mol) for compounds 1-4 in gas phase and water solvated (PCM) phase.

\begin{tabular}{lccccc}
\hline Comp & $\mathrm{R} 1$ & $\mathrm{R} 2$ & $\mathrm{BDE}(\mathrm{O}-\mathrm{H})$ gas phase & BDE $(\mathrm{O}-\mathrm{H})$ PCM water phase & $\mathrm{IC}_{50}(\mathrm{mM}) \mathrm{TA3}^{\mathrm{a}}$ \\
\hline $\mathbf{1}$ & $\mathrm{H}$ & $\mathrm{H}$ & 87.08 & 87.92 & Inactive \\
$\mathbf{2}$ & $\mathrm{H}$ & $\mathrm{Me}$ & 86.81 & 87.80 & Inactive \\
$\mathbf{3}$ & $\mathrm{Cl}$ & $\mathrm{H}$ & 87.64 & 86.94 & $0.12 \pm 0.003$ \\
$\mathbf{4}$ & $\mathrm{Cl}$ & $\mathrm{Me}$ & 86.84 & 86.77 & $0.12 \pm 0.006$ \\
\hline \multicolumn{2}{l}{ a Data taken from [27]. } & & &
\end{tabular}

prooxidants [24]. Their ability to inhibit the growth and proliferation of certain malignant cells in vitro is strongly dependent on their structural characteristics [25]. These are two main mechanisms which may be closely related to the biological activities displayed by the compounds studied here.

Previously, we have described that the oxygen uptake inhibition by mouse mammary adenocarcinoma TA3/Ha cancer cells can be used as a quick test for preliminary screening of possible anticancer activity. Generally, $\mathrm{IC}_{50}$ for oxygen uptake inhibition is about one order of magnitude greater than $\mathrm{IC}_{50}$ for cytotoxicity [26] when a mitochondrial effect is involved. Based on these antecedents, we screened a set of simple and angular chromones for the inhibition of oxygen consumption by TA3/Ha tumor cells [27]. An interesting result arising from that study shows the mandatory presence of chlorine atom on angular structures to exert an effect on the respiration of tumor cells. IC50 values for oxygen uptake by chromones 3 and $\mathbf{4}$ (Table 1) are similar to that exhibited by a tricyclic hydroquinone, previously studied by us [28, 29], which exhibited cell cycle arrest and inhibits complex Idependent respiration with selective antiproliferative effect on mouse mammary adenocarcinoma TA3/Ha cancer cells.

To explain the differences among the biological activities of these compounds, in this work we pursued to gain insight about the role of the chlorine atom on the chemical reactivity of the neutral molecules and also on the reactivity of free radicals generated from them. The main parameters to evaluate the free radical behavior of chromones 1-4 (Table 1), namely, bond dissociation energies (BDE) and spin density (SD), were assessed through density functional theory (DFT) calculations at M06-2x/6-311+G(d,p) level. Moreover, the reactivity of the chromones towards nucleophiles was studied through Fukui and Parr functions for nucleophilic attack.

\section{Material and Methods}

The calculations were carried out using the Gaussian09 program package [30]. All molecules and their radicals were optimized at density functional theory (DFT) M06-2x/6$311+\mathrm{G}(\mathrm{d}, \mathrm{p})$ level. The bond dissociation enthalpy (BDE) for the $\mathrm{O}-\mathrm{H}$ homolytic bond breaking was calculated as follows:

$$
\mathrm{BDE}=\mathrm{H}\left(\mathrm{RO}^{\bullet}\right)+\mathrm{H}\left(\mathrm{H}^{\bullet}\right)-\mathrm{H}(\mathrm{ROH})
$$

where $\mathrm{H}(\mathrm{ROH}), \mathrm{H}\left(\mathrm{RO}^{\bullet}\right)$, and $\mathrm{H}\left(\mathrm{H}^{\bullet}\right)$ are the enthalpies of the neutral molecules, their radicals, and the $\mathrm{H}$-atom, respectively.<smiles>[R]C1=C([R])Cc2c(c(O)c([R])c3c(=O)c(C=O)coc23)C1</smiles>

1-4

Figure 1: Structure of molecules 1-4 studied in this work.

Local reactivity indices, Fukui function $\left(f^{+}\right)$and Parr function $\left(P^{+}\right)$, for electrophilic attack were calculated as previously described [31,32].

\section{Results}

3.1. Free Radicals Properties. A computational study about some properties of the free radicals from the phenolic compounds 1-4 (Figure 1) was carried out. Bond dissociation enthalpy (BDE) associated with the bond breaking of labile atoms (e.g., hydrogen in the $\mathrm{O}-\mathrm{H}$ bond) that lead to formation of radical species is the main parameter related to hydrogen atom transfer (HAT), the most important mechanism of antioxidant activity. Lower BDE values are associated with higher antioxidant activities of the molecules [33]. Table 1 shows the BDE values calculated in gas phase and in aqueous medium (polarizable continuum medium, PCM). Gas phase values show a higher $\mathrm{BDE}$ for compounds $\mathbf{1}$ and 3, with $\mathrm{R}_{2}=\mathrm{H}$, while compounds 2 and 4 , with $\mathrm{R}_{2}=\mathrm{Me}$, present lower BDE. Nevertheless, when water solvation is included, the trend changes and compounds 1 and 2 , with $R_{1}=H$, present higher BDE than 3 and $\mathbf{4}$, with $\mathrm{R}_{1}=\mathrm{Cl}$. The last result is according to the capability of oxygen uptake inhibition by mouse mammary adenocarcinoma TA3/Ha cancer cells (Table 1).

On the other hand, the stability of the free radicals is also a key factor related to their antioxidant activity. To obtain information about the stability of the free radicals generated from the studied compounds, spin densities (SD) were calculated for the four radical species formed by the abstraction of the hydrogen atom from the $\mathrm{O}-\mathrm{H}$ bond. When $\mathrm{SD}$ is more delocalized, the formation of the radical is easier. $\mathrm{SD}$ and BDE are correlated; when SD is lower BDE also tend 

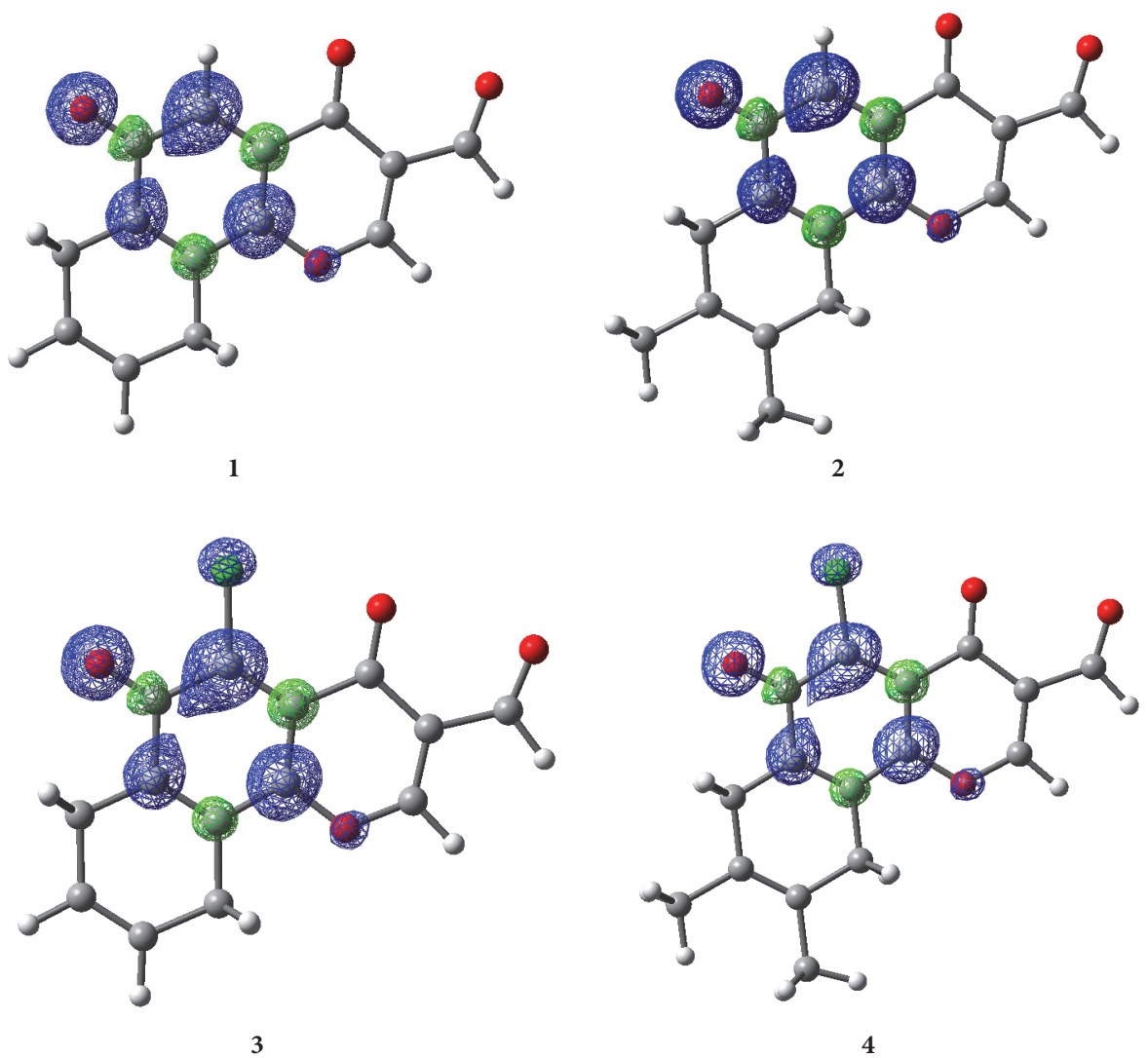

FIGURE 2: Spin density isosurface (isovalue $=0.004$ ) for four radical molecules (water PCM solvated). Blue indicates positive and green indicates negative spin density values.

TABLE 2: Spin densities on carbons 1, 2, 3, and 4 both in gas phase and water (PCM) solvated.

\begin{tabular}{lcccccccc}
\hline \multirow{2}{*}{ Molecule } & \multicolumn{9}{c}{ Spin density } \\
& \multicolumn{9}{c}{ Gas phase } & \multicolumn{4}{c}{ Water phase } \\
& C1 & C2 & C3 & O4 & C1 & C2 & C3 & O4 \\
\hline $\mathbf{1}$ & 0.158 & 0.200 & 0.287 & 0.650 & 0.199 & 0.305 & 0.392 & 0.356 \\
$\mathbf{2}$ & 0.200 & 0.192 & 0.280 & 0.650 & 0.226 & 0.293 & 0.394 & 0.357 \\
$\mathbf{3}$ & 0.141 & 0.209 & 0.280 & 0.602 & 0.157 & 0.299 & 0.371 & 0.315 \\
$\mathbf{4}$ & 0.164 & 0.201 & 0.287 & 0.603 & 0.171 & 0.292 & 0.385 & 0.316 \\
\hline
\end{tabular}

to be lower. Additionally, SD provides information about site reactivity in the radical molecule.

In Figure 2 the SD isosurfaces for the four radical molecules are displayed. The SD is mainly located on the aromatic ring in all cases. The presence of chlorine in molecules $\mathbf{3}$ and $\mathbf{4}$ polarizes some SD towards itself, leading to a more delocalized SD distribution.

Atoms with higher SD values are presented in Table 2. In gas phase, the atom with highest $\mathrm{SD}$ is $\mathrm{O} 4$ in all cases. Molecules 1 and 2 present similar values of SD on O4, and higher than $\mathrm{SD}$ on $\mathrm{O} 4$ of molecules 3 and $\mathbf{4}$, which also present similar values between them. C3 presents the second higher SD, with $\mathbf{1}$ and $\mathbf{4}$ being higher than $\mathbf{2}$ and $\mathbf{3}$. On the other hand, considering water solvation, the results are quite
Table 3: Fukui $\left(f^{+}\right)$and Parr $\left(P^{+}\right)$functions for the nucleophilic attack at carbons 5,6 , and 7 .

\begin{tabular}{lcccccc}
\hline \multirow{2}{*}{ Molecule } & \multicolumn{3}{c}{$f^{+}$} & & & $P^{+}$ \\
& C5 & C6 & C7 & C5 & C6 & C7 \\
\hline $\mathbf{1}$ & 0.217 & 0.156 & -0.054 & 0.752 & 0.110 & 0.099 \\
$\mathbf{2}$ & 0.192 & 0.183 & 0.064 & 0.751 & 0.114 & 0.094 \\
$\mathbf{3}$ & 0.165 & 0.113 & 0.048 & 0.262 & 0.044 & 0.151 \\
$\mathbf{4}$ & 0.072 & 0.129 & 0.080 & 0.122 & 0.038 & 0.169 \\
\hline
\end{tabular}

different. In this case $\mathrm{C} 3$ presents the highest SD in all cases. Molecules 1 and $\mathbf{2}$ (without chlorine) present higher values of SD on C3 compared with molecules 3 and 4 . The effect of chlorine atom is to decrease the SD on C3 for molecules 3 and 4 , which led to a more delocalized SD distribution and can explain the lower BDE observed in these molecules. These results also highlight the importance of the solvent to explain the antioxidant properties of these compounds and hence their biological activities.

3.2. Electrophilic Reactivity. In order to explore if the electrophilic reactivity of the four chromones towards biological nucleophiles, which could also explain the biological activity exerted by these compounds, Fukui $\left(f^{+}\right)$and Parr $\left(P^{+}\right)$ functions were calculated (Table 3 ). We focus on the atoms 
that can suffer a nucleophilic attack; carbon 5 can experience 1,4-addition, while carbons 6 and 7 can experience 1,2addition. According to $f^{+}$, C5 is the most reactive site in molecules 1, 2, and $\mathbf{3}$ for a nucleophilic attack, while C6 is the most reactive site in molecule 4 . On the other hand, according to $P^{+} \mathrm{C} 5$ is more susceptible for a nucleophilic attack in molecules 1, 2, and 3 while for molecule $4 \mathrm{C} 7$ is the most reactive. Although $f^{+}$and $P^{+}$commonly give a similar trend; in some cases $f^{+}$has generated some errors where $P^{+}$ have predicted correctly the experimental results [32]. These results also highlight the effect of the presence of the chlorine atom, which can modify the local electrophilic reactivity in electrophilic atoms and can account to explain the difference in their biological activities.

\section{Conclusions}

In this work, the free radicals behavior (BDE and SD) and electrophilic reactivity $\left(f^{+}\right.$and $\left.P^{+}\right)$of a series of four chromones, which have previously shown antiproliferative activity towards mouse mammary adenocarcinoma TA3/Ha cancer cells, were explored. The presence of a chlorine atom on the aromatic carbon C3 is shown to be mandatory for the antiproliferative activity of these molecules.

The BDE for the O-H bond is shown to be lower for chromones possessing a chlorine atom on C3 (3 and 4) when water solvation was included. The latter supported a possible implication of radical species of these molecules in their antiproliferative activity. Moreover, the effect of chlorine atom decreases the SD on C3 for molecules $\mathbf{3}$ and 4 when water solvation was considered, which led to a more delocalized SD distribution and can explain the lower BDE for these molecules. Besides, local electrophilic reactivity results showed that the presence of chlorine atom, which modifies the local electrophilic reactivity in electrophilic atoms, could also account to explain the difference in their biological activities. The results of this study have potential implications for the design of chromone analogues as anticancer compounds.

\section{Competing Interests}

The authors declare that they have no competing interests.

\section{Acknowledgments}

The authors are grateful to Fondo Nacional de Desarrollo Científico y Tecnológico (FONDECYT) Grant 1140753. Powered@NLHPC: This research was partially supported by the supercomputing infrastructure of the NLHPC (ECM-02).

\section{References}

[1] A. Gaspar, M. J. Matos, J. Garrido, E. Uriarte, and F. Borges, "Chromone: a valid scaffold in medicinal chemistry," Chemical Reviews, vol. 114, no. 9, pp. 4960-4992, 2014.

[2] J. A. Beutler, E. Hamel, A. J. Vlietinck et al., "Structure-activity requirements for flavone cytotoxicity and binding to tubulin,"
Journal of Medicinal Chemistry, vol. 41, no. 13, pp. 2333-2338, 1998.

[3] L.-C. Lin, Y.-C. Kuo, and C.-J. Chou, "Cytotoxic biflavonoids from Selaginella delicatula," Journal of Natural Products, vol. 63, no. 5, pp. 627-630, 2000.

[4] P. Valenti, A. Bisi, A. Rampa et al., "Synthesis and biological activity of some rigid analogues of flavone-8- acetic acid," Bioorganic and Medicinal Chemistry, vol. 8, no. 1, pp. 239-246, 2000.

[5] R. Larget, B. Lockhart, P. Renard, and M. Largeron, "A convenient extension of the Wessely-Moser rearrangement for the synthesis of substituted alkylaminoflavones as neuroprotective agents in vitro," Bioorganic and Medicinal Chemistry Letters, vol. 10, no. 8, pp. 835-838, 2000.

[6] J. S. Yoon, M. K. Lee, S. H. Sung, and Y. C. Kim, "Neuroprotective 2-(2-phenylethyl)chromones of Imperata cylindrica," Journal of Natural Products, vol. 69, no. 2, pp. 290-291, 2006.

[7] A. Groweiss, J. H. Cardellina II, and M. R. Boyd, "HIVInhibitory prenylated xanthones and flavones from Maclura tinctoria," Journal of Natural Products, vol. 63, no. 11, pp. 15371539, 2000.

[8] D. L. Yu, C. H. Chen, A. Brossi, and K. H. Lee, "Anti-AIDS agents. $60 . \dagger$ substituted $3^{\prime} \mathrm{R}, 4^{\prime} \mathrm{R}-\mathrm{Di}$-O-(-)-camphanoyl- $2^{\prime}, 2^{\prime}$ dimethyldihydropyrano[2,3-f]chromone (DCP) analogues as potent anti-HIV agents," Journal of Medicinal Chemistry, vol. 47, no. 16, pp. 4072-4082, 2004.

[9] Y. Deng, J. P. Lee, M. Tianasoa-Ramamonjy et al., "New antimicrobial flavanones from Physena madagascariensis," Journal of Natural Products, vol. 63, no. 8, pp. 1082-1089, 2000.

[10] W. G. Ma, N. Fuzzati, S. L. Lu, D. S. Gu, and K. Hostettmann, "Further chromones from Eriosema tuberosum," Phytochemistry, vol. 43, no. 6, pp. 1339-1343, 1996.

[11] P.-G. Pietta, "Flavonoids as antioxidants," Journal of Natural Products, vol. 63, no. 7, pp. 1035-1042, 2000.

[12] N. Phosrithong, W. Samee, P. Nunthanavanit, and J. Ungwitayatorn, "In vitro antioxidant activity study of novel chromone derivatives," Chemical Biology and Drug Design, vol. 79, no. 6, pp. 981-989, 2012.

[13] O. Bozdag-Dundar, M. Ceylan-Unlusoy, E. J. Verspohl, and R. Ertan, "Synthesis and antidiabetic activity of some new chromonyl-2,4-thiazolidinediones," Arzneimittel Forschung, vol. 57, pp. 532-536, 2007.

[14] M. Ceylan-Ünlüsoy, E. J. Verspohl, and R. Ertan, "Synthesis and antidiabetic activity of some new chromonyl-2,4- thiazolidinediones," Journal of Enzyme Inhibition and Medicinal Chemistry, vol. 25, no. 6, pp. 784-789, 2010.

[15] S. H. Kim, Y. H. Lee, S. Y. Jung, H. J. Kim, C. Jin, and Y. S. Lee, "Synthesis of chromone carboxamide derivatives with antioxidative and calpain inhibitory properties," European Journal of Medicinal Chemistry, vol. 46, no. 5, pp. 1721-1728, 2011.

[16] K. Iwagoe, S. Kodama, T. Konishi, S. Kiyosawa, Y. Fujiwara, and Y. Shimada, "The structures of ah15 and ah18, new bi-phenylethylchromones and tri-phenylethylchromones from agalwood," Chemical and Pharmaceutical Bulletin, vol. 35, no. 11, pp. 4680-4682, 1987.

[17] W. Ren, Z. Qiao, H. Wang, L. Zhu, and L. Zhang, "Flavonoids: promising anticancer agents," Medicinal Research Reviews, vol. 23, no. 4, pp. 519-534, 2003.

[18] A. Cimini, M. d’Angelo, E. Benedetti et al., "Flavopiridol: an old drug with new perspectives? Implication for development 
of new drugs," Journal of Cellular Physiology, vol. 232, no. 2, pp. 312-322, 2017.

[19] D. Enders, G. Geibel, and S. Osborne, "Diastereo- and enantioselective total synthesis of stigmatellin A," Chemistry, vol. 6, no. 8, pp. 1302-1309, 2000.

[20] H. Miyoshi, "Inhibitors of mitochondrial respiratory enzymes," Journal of Pesticide Science, vol. 30, no. 2, pp. 120-132, 2005.

[21] S. D. Lindell, O. Ort, P. Lümmen, and R. Klein, “The design and synthesis of novel inhibitors of NADH: ubiquinone oxidoreductase," Bioorganic and Medicinal Chemistry Letters, vol. 14, no. 2, pp. 511-514, 2004.

[22] H. Radeke, K. Hanson, P. Yalamanchili et al., "Synthesis and biological evaluation of the mitochondrial complex 1 inhibitor 2[4-(4-fluorobutyl)benzylsulfanyl]-3-methylchromene-4-one as a potential cardiac positron emission tomography tracer," Journal of Medicinal Chemistry, vol. 50, no. 18, pp. 4304-4315, 2007.

[23] R. Araya-Maturana, J. Heredia-Moya, C. A. Escobar, and P. Pérez, "On the reduction of 4-oxo-4H-benzopyran-3carbaldehydes: global and local electrophilicity patterns," Journal of the Chilean Chemical Society, vol. 49, no. 1, pp. 35-38, 2004.

[24] G. Cao, E. Sofic, and R. L. Prior, "Antioxidant and prooxidant behavior of flavonoids: structure-activity relationships," Free Radical Biology and Medicine, vol. 22, no. 5, pp. 749-760, 1997.

[25] E. Sergediene, K. Jönsson, H. Szymusiak, B. Tyrakowska, I. M. C. M. Rietjens, and N. Čenas, "Prooxidant toxicity of polyphenolic antioxidants to HL-60 cells: description of quantitative structure-activity relationships," FEBS Letters, vol. 462, no. 3, pp. 392-396, 1999.

[26] R. Araya-Maturana, W. Cardona, B. K. Cassels et al., "Effects of 9,10-dihydroxy-4,4-dimethyl-5,8-dihydro- $1(4 \mathrm{H})$-anthracenone derivatives on tumor cell respiration," Bioorganic and Medicinal Chemistry, vol. 14, no. 13, pp. 4664-4669, 2006.

[27] R. Araya-Maturana, J. Heredia-Moya, O. Donoso-Tauda et al., "Effects of simple and angular chromones on tumor cell respiration," Natural Product Communications, vol. 3, no. 4, pp. 519-524, 2008.

[28] R. Araya-Maturana, T. Delgado-Castro, M. Gárate et al., "Effects of 4,4-dimethyl-5,8-dihydroxynaphtalene-1-one and 4,4dimethyl-5,8-dihydroxytetralone derivatives on tumor cell respiration," Bioorganic and Medicinal Chemistry, vol. 10, no. 9, pp. 3057-3060, 2002.

[29] F. A. Urra, M. Martínez-Cifuentes, M. Pavani et al., "An orthocarbonyl substituted hydroquinone derivative is an anticancer agent that acts by inhibiting mitochondrial bioenergetics and by inducing $\mathrm{G}_{2} / \mathrm{M}$-phase arrest in mammary adenocarcinoma TA3," Toxicology and Applied Pharmacology, vol. 267, no. 3, pp. 218-227, 2013.

[30] M. J. Frisch, G. W. Trucks, H. B. Schlegel et al., Revision a.01, Gaussian 09, Gaussian Inc, Wallingford, Conn, USA, 2009.

[31] R. G. Parr and W. Yang, "Density functional approach to the frontier-electron theory of chemical reactivity," Journal of the American Chemical Society, vol. 106, no. 14, pp. 4049-4050, 1984.

[32] L. R. Domingo, P. Pérez, and J. A. Sáez, "Understanding the local reactivity in polar organic reactions through electrophilic and nucleophilic Parr functions," RSC Advances, vol. 3, no. 5, pp. 1486-1494, 2013.

[33] M. Leopoldini, N. Russo, and M. Toscano, "The molecular basis of working mechanism of natural polyphenolic antioxidants," Food Chemistry, vol. 125, no. 2, pp. 288-306, 2011. 

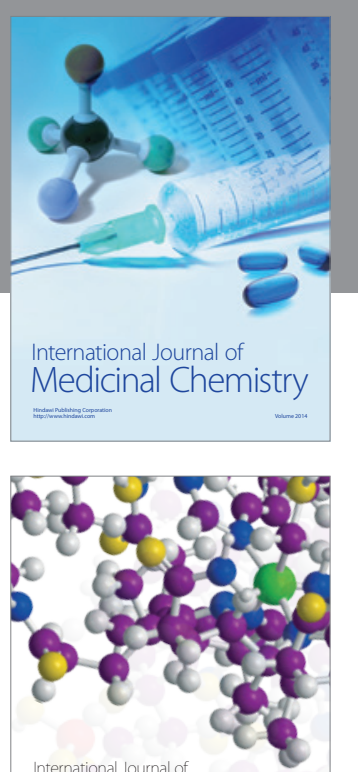

Carbohydrate Chemistry

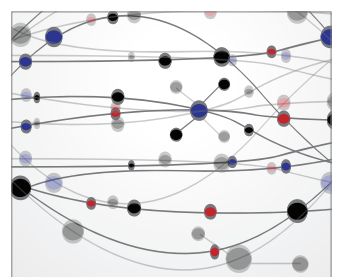

The Scientific World Journal
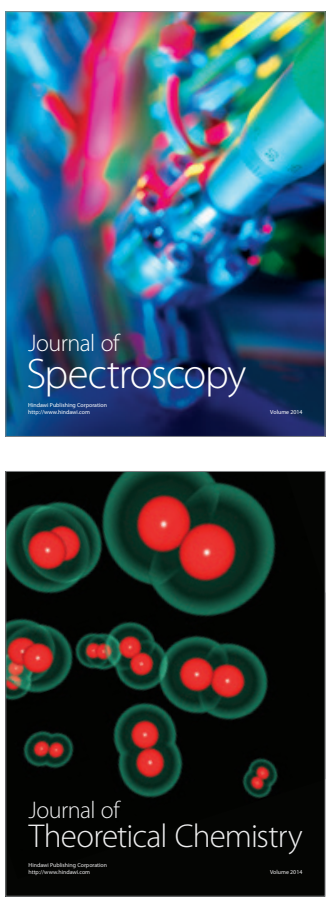
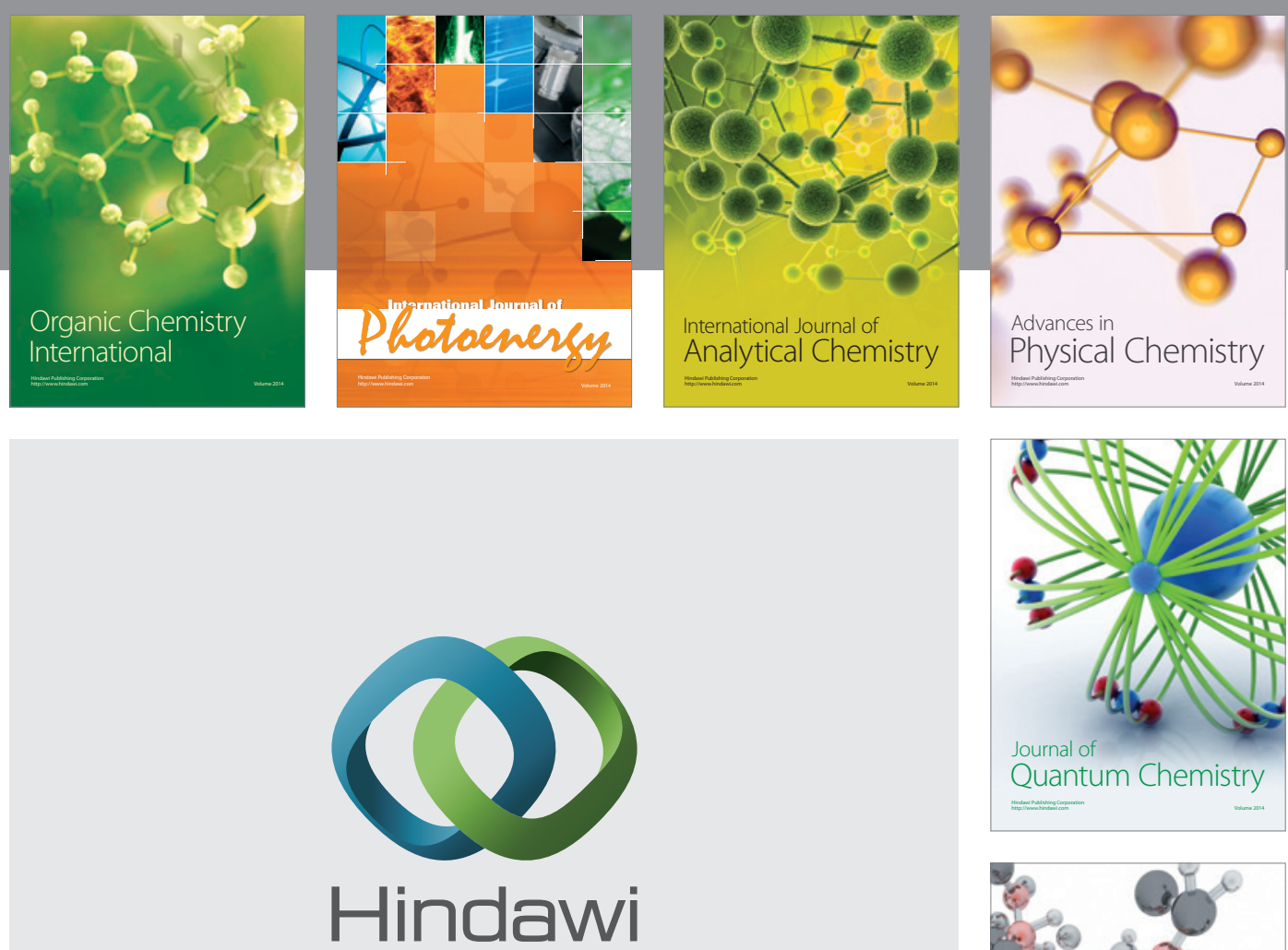

Submit your manuscripts at

https://www.hindawi.com

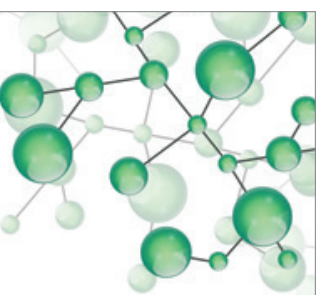

International Journal of

Inorganic Chemistry
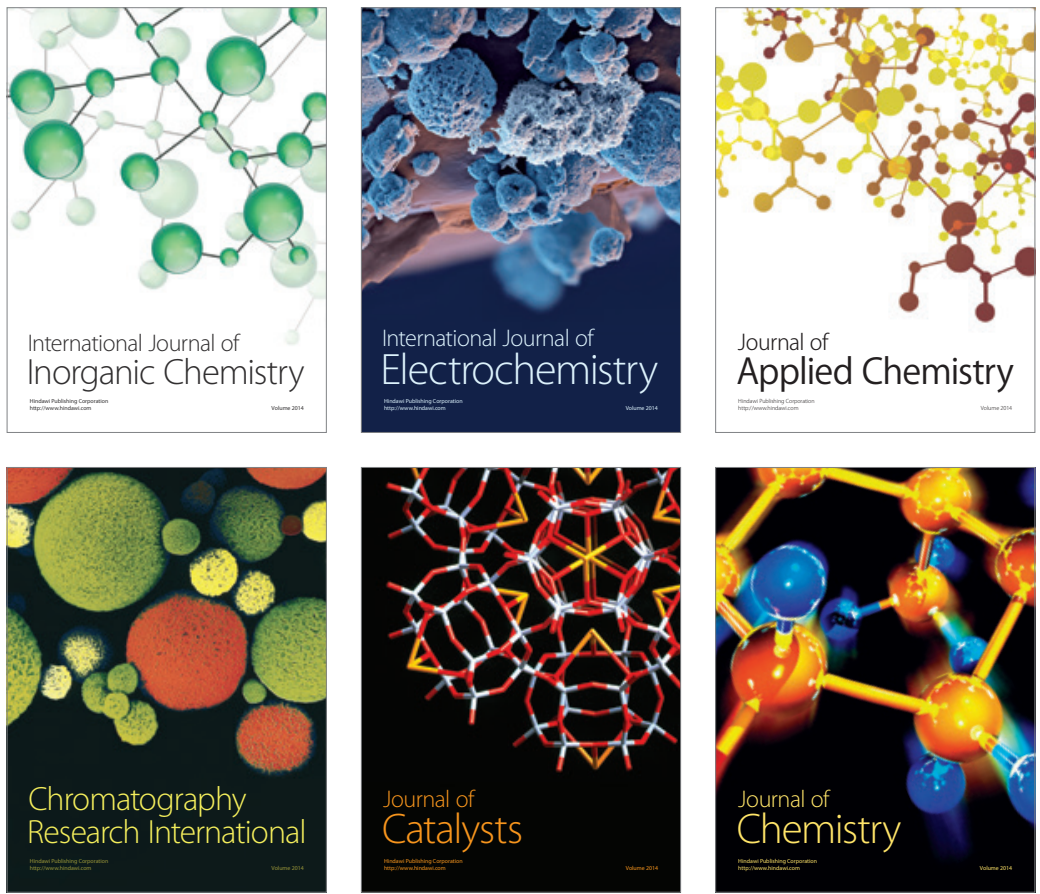

Journal of

Applied Chemistry
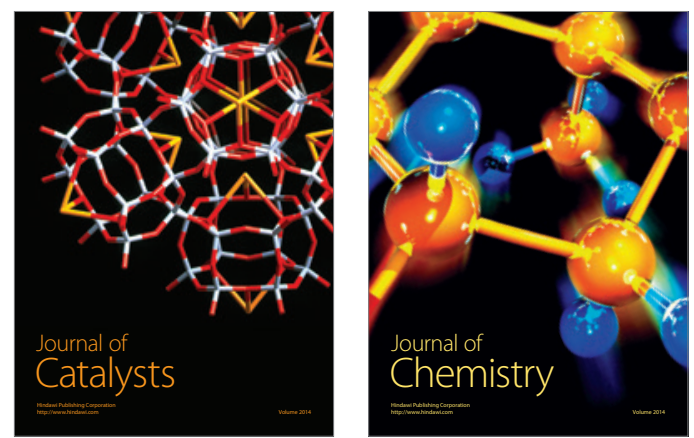
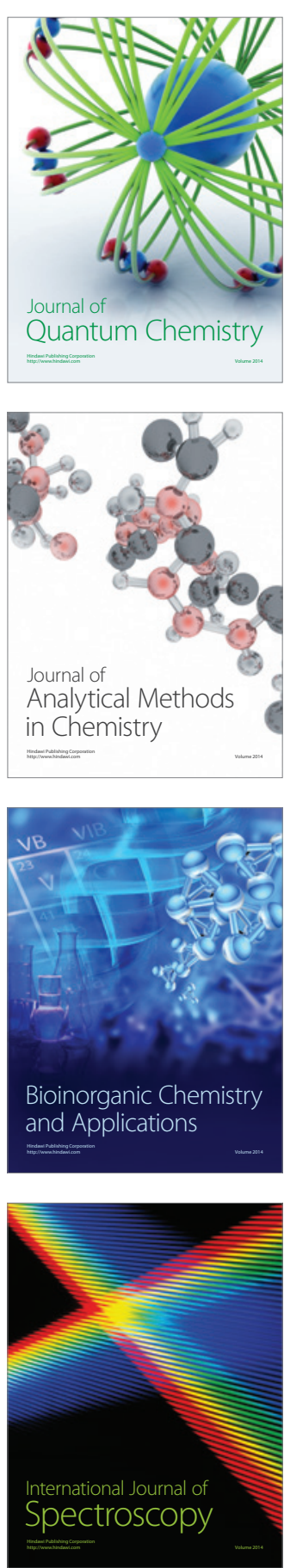